\title{
¿ES POSIBLE REPETIR LAS VOTACIONES PARLAMENTARIAS? ¿VOTA EL DIPUTADO O EL GRUPO PARLAMENTARIO? A PROPÓSITO DE LA STC 361/2006
}

\author{
PIEDAD GARCÍA-ESCUDERO MÁRQUEZ \\ Letrado de las Cortes Generales \\ Profesora Titular de Derecho Constitucional \\ Universidad Complutense de Madrid
}

A Mercedes Araújo

\author{
SUMARIO \\ I. Circunstancias de hecho. \\ II. Cuestiones planteadas en la sentencia. \\ III. Otras cuestiones.
}

\section{CIRCUNSTANCIAS DE HECHO}

La STC 361/2006, de 18 de diciembre, resuelve un asunto de gran impacto político y mediático. El recurso de amparo 1357/2005 fue interpuesto por una diputada socialista al Parlamento Vasco y el portavoz de su grupo parlamentario (Socialistas Vascos) contra la decisión adoptada por el Presidente del Parlamento, en el curso de una sesión plenaria, de no repetir determinada votación, decisión que la Mesa se negó a reconsiderar.

La relevancia de la votación estribaba en su objeto (el voto particular presentado por cuatro grupos parlamentarios al dictamen — de supresión del articulado- sobre el Proyecto de Ley de Presupuestos Generales de la Comunidad Autónoma del País Vasco para 2005, cuyo rechazo hubiera supuesto el del propio Proyecto) y en lo ajustado de las posiciones existentes en el seno de la Cámara, de tal manera que el no cómputo del voto de la recurrente fue fundamental para que dicho voto particular fuera aprobado, y en consecuencia también los Presupuestos. 
Sucintamente expuestos, y en cierta medida reconstruidos a partir de la exposición de antecedentes contenida en la Sentencia, del Diario de Sesiones y de los documentos sobre la tramitación obrantes en la web del Parlamento Vasco (entre los que no se encuentran los informes citados en aquélla), los hechos acaecidos serían los siguientes:

a) El 28 de diciembre de 2004, convocada sesión plenaria del Parlamento Vasco para debatir el dictamen sobre el Proyecto de Ley de Presupuestos Generales de la Comunidad Autónoma para 2005, tras los turnos de intervención de los portavoces de los grupos parlamentarios, el Presidente de la Cámara somete a votación el voto particular presentado por los Grupos Nacionalista Vasco, Eusko Alkartasuna, Mixto de Izquierda Unida y Mixto de Unidad Alavesa, cuyo rechazo podría haber supuesto la aprobación del dictamen de la Comisión de Economía, Hacienda y Presupuestos, a su vez de rechazo al Proyecto de Ley de Presupuestos, en la medida en que suprimía todo su articulado.

Estando presentes 74 diputados, número par, el empate a 37 votos, de conformidad con el artículo 80.1 del Reglamento del Parlamento Vasco (RPV), provocaría la repetición de la votación, y si resultara nuevo empate, se volvería a votar en la sesión próxima; si también entonces hubiera empate, se entendería rechazado el objeto de aquella.

b) La votación, como es usual en las ordinarias, se desarrolló mediante procedimiento electrónico. En los términos que figuran en la demanda de amparo, al ir a emitir su voto la parlamentaria recurrente, comprobó que el sistema electrónico que tenía instalado en su escaño no funcionaba, por lo que hizo ostensibles gestos en este sentido tanto al portavoz de su grupo (también recurrente) como al Presidente de la Cámara.

Transcurrido el tiempo concedido para la votación, el resultado que apareció en el panel electrónico es el siguiente: 73 parlamentarios presentes, 37 votos a favor, 36 en contra y 0 abstenciones, por lo que el Presidente de la Cámara dio por aprobado el voto particular.

c) El portavoz socialista solicitó la palabra para indicar que su compañera de grupo había intentado activar el sistema de votación, pero no había conseguido hacerlo, por lo que no había sido computada su presencia ni el sentido de su voto, que pretendía ser contrario al voto particular.

Sigue un diálogo entre el portavoz y el Presidente, que la Sentencia declara recogido en "el acta de la sesión, levantada por los servicios de documentación del Parlamento Vasco", sin que se aluda al Diario de Sesiones ni a la grabación de la sesión, pese a que el artículo 98.1 RPV declara que se reproducirán íntegramente en aquél, dejando constancia de las incidencias producidas, todas las intervenciones y acuerdos adoptados en las sesiones públicas, y que el párrafo 2 de este artículo hace mención a los registros gráficos y sonoros, bien es verdad que en referencia a las sesiones secretas.

No reproducimos este diálogo, aunque creemos que contiene algunos elementos que habrían podido ser esenciales para la resolución del recurso (volveremos sobre ello más adelante), pero el resultado es que el Presidente 
no accede a la petición de repetición de la votación que se le formula, subsanando las deficiencias técnicas que impidieron a la parlamentaria emitir su voto, pese a la invocación de anteriores precedentes (de repetición, parece). La sesión continúa con la votación de las enmiendas aprobadas en la Comisión y de las reservadas para el Pleno, proclamando aprobada la Ley (dos veces, la primera cuando faltaban unas enmiendas por votar, véase D. S. P.V, núm. 112, pág. 68.)

d) Presentado escrito de reconsideración ante la Mesa de la Cámara (de conformidad con el artículo 23.2 RPV, si un parlamentario o un grupo discrepa de la decisión adoptada por la Mesa en el ejercicio de las funciones de calificación, admisión a trámite y tramitación de documentos, podrá solicitar su reconsideración, decidiendo aquella definitivamente, oida la Junta de Portavoces, mediante resolución motivada), ésta toma conocimiento, manifestando el Presidente en el debate habido en el seno de la misma que, de acuerdo con el Reglamento, la Mesa no puede reconsiderar las decisiones por él adoptadas en el curso de una sesión plenaria, criterio que comparten el Vicepresidente $1 .^{\circ}$ y la Secretaria $2 .^{\mathrm{a}}$.

Mediante certificación posterior, la Mesa se ratifica en que carece de atribuciones para revisar las decisiones tomadas por el Presidente de la Cámara en el curso de una sesión plenaria, lo que suponía el carácter definitivo de la decisión presidencial, con la consiguiente apertura del recurso de amparo.

e) La demanda de amparo se fundamenta en la supuesta vulneración del derecho al desempeño en condiciones de igualdad del cargo representativo de parlamentario, reconocido en el artículo $23 \mathrm{CE}$, en cuanto que la decisión del Presidente impidió a la parlamentaria de modo efectivo el ejercicio de su derecho de voto, resultando además finalmente aprobado como ley un proyecto presupuestario en contra de su voluntad, lo que no hubiera ocurrido de haberse computado el voto y el sentido del mismo.

El portavoz del Grupo Socialista alega la violación del mismo derecho fundamental, porque, de haberse computado el voto de la parlamentaria, en el mismo sentido que el resto de su grupo, se habría llegado a un empate que habría impedido la aprobación de un proyecto de ley con el que su grupo no estaba de acuerdo.

De las alegaciones posteriores de los demandantes, cabe destacar la referencia a la falta de motivación de la decisión presidencial.

f) El Ministerio Fiscal interesa el otorgamiento del amparo por vulneración del derecho fundamental al ejercicio de las funciones parlamentarias en condiciones de igualdad, en el caso de la parlamentaria, por no haberle permitido el ejercicio de su derecho al voto, estando en pleno ejercicio de sus funciones y presente en el momento de la votación; en el caso del portavoz, en tanto que al grupo parlamentario se le había privado de sumar un voto concurrente con el resto de los miembros, que hubiera supuesto decisivamente la no aprobación de un proyecto de ley con el que habían mostrado su desacuerdo en el trámite de intervenciones que había precedido al acto de la votación. 
g) Las alegaciones del Parlamento Vasco, formuladas por el Letrado Mayor, califican de incorrecta la conclusión de la demanda sobre fallos del sistema electrónico, considerando lo más probable que fuera la introducción tardía de la tarjeta necesaria para el funcionamiento del mismo la que impidió que la parlamentaria pudiera participar en la votación.

De ello deriva que la actuación de la parlamentaria no se adecuó a la diligencia exigible y, en esas condiciones, no habría habido conculcación del derecho a la participación política incluido en el artículo 23.2, dado que el RPV reconoce el derecho al voto pero no a la repetición de una votación, y que el derecho al voto no es omnímodo, sino que tiene que ejercerse de acuerdo con los sistemas y requisitos que establece el propio Reglamento. El procedimiento electrónico de votación requiere una mínima diligencia y atención; si no se da ésta y el parlamentario no puede votar, no existe un derecho a repetir la votación.

La representación del Parlamento Vasco niega que existan precedentes de soluciones contrarias (se alude a los criterios establecidos en un informe de los servicios jurídicos de la Cámara sobre eventuales anulaciones de votaciones electrónicas) y no admite que el acuerdo del Presidente fuera inmotivado. Recuerda que estar siempre a la "voluntad auténtica" abre un amplio campo de posibilidades al obstruccionismo parlamentario, la inseguridad y la confusión, y aduce la existencia de frecuentes errores en las Cámaras parlamentarias de los que da ejemplos, señalando que las repeticiones quedan descartadas.

\section{CUESTIONES PLANTEADAS EN LA SENTENCIA}

En una breve argumentación jurídica, de apenas cuatro páginas, poco más que las dedicadas a la descripción de los hechos, el Tribunal Constitucional se centra en dos cuestiones:

a) Si la negativa a la repetición de la votación lesionó el derecho al voto de la diputada.

b) Si el portavoz del Grupo Socialista estaba legitimado para interponer el recurso de amparo.

Nos ocupamos de estas dos cuestiones por separado, y a continuación de algunas otra que, incidentalmente, nos suscita la Sentencia.

\section{El Derecho al Voto y las Responsabilidades de la PResidencia}

a) La posición del Tribunal

En cuanto a la primera cuestión, el Tribunal recuerda su doctrina sobre el artículo 23.2 CE como derecho de configuración legal y la relevancia consti- 
tucional de las lesiones del ius in officium sólo en cuanto afecten al núcleo de la función representativa.

Partiendo de ello, afirma que, sin duda, el derecho al voto de los parlamentarios es uno de los que se integran en su ius in officium, como consecuencia de la naturaleza misma de las cosas: siendo uno de sus principales derechos/deberes la participación en las tareas de las Cámaras, la forma más habitual de concretar la misma es el ejercicio del derecho al voto, con el que manifiestan su postura en los acuerdos de las Cámaras. Así resulta también del propio Reglamento del Parlamento Vasco.

El Tribunal realiza a continuación la afirmación más relevante, en cuanto a los efectos posteriores que pueda tener sobre el funcionamiento de las Cámaras: reconociendo que ha sido controvertido si en realidad se dio un funcionamiento defectuoso de los sistemas de votación (lo que niega la representación del Parlamento Vasco) o si, por el contrario, los problemas se debieron a una supuesta negligencia de la parlamentaria, declara:

"Al respecto conviene aclarar, en primer término, que, dadas las circunstancias del caso, en que resulta afectado, como después se dirá, el derecho fundamental de un parlamentario, recae sobre los órganos de la Cámara, y en especial sobre su Presidente, la tarea de demostrar que la Diputada tuvo una conducta negligente. Puede presumirse, por contra, que, salvo prueba indubitable en contrario, la misma actuó correctamente, entre otras cosas porque ningún interés puede suponérsele en crear una situación en la que ella y su grupo fueron los principales perjudicados. De los datos que constan en el expediente, $y$ de las alegaciones hechas por las partes, se deduce que no se ha podido probar, de manera irrebatible, que la Sra. Novales cometiera un error durante el desarrollo de la votación."

Partiendo de esta afirmación, que constituye el núcleo de su argumentación, el Tribunal declara que es vulnerado el art. 23.2 CE si los propios órganos de las Asambleas impiden o coartan su práctica o adoptan decisiones que contrarien la naturaleza de la representación o la igualdad de los representantes. Tales circunstancias imponen a los órganos parlamentarios una interpretación restrictiva de todas aquellas normas que puedan suponer una limitación al ejercicio de aquellos derechos o atribuciones que integran el status constitucionalmente relevante del representante público y el deber de motivar las razones de su aplicación, so pena, no sólo de vulnerar el derecho fundamental del representante de los ciudadanos a ejercer su cargo (art. 23.2 CE), sino también de infringir el de éstos a participar en los asuntos públicos (art. 23.1 CE)" [recientemente, STC 90/2005, de 18 de abril, FJ 2 b) y las numerosas en ella citadas]".

De ello concluye que "la actuación de la presidencia del Parlamento Vasco supuso, pura y simplemente, lesionar el derecho a votar de la parlamentaria. No es lógico entender que, ante un problema técnico, que puede suceder con mayor o menor frecuencia en ese tipo de sistemas electrónicos y sin que por otra parte haya quedado fehacientemente demostrado que se tratara 
de una negligencia de la Diputada, la única reacción presidencial fuera la negativa a la comprobación de la anomalia en ese momento y a la repetición, en su caso, de la votación controvertida, con las graves consecuencias que ello implicaba para el resultado de la misma y para el conocimiento de la auténtica voluntad de la Cámara en tema tan trascendente para la Comunidad Autónoma del País Vasco como era la aprobación de su Ley de presupuestos. Es patente, por tanto, que ha existido una vulneración del derecho de la Sra. Novales al ejercicio de sus funciones en condiciones de igualdad, reconocido en el art. 23.2 CE, y este aspecto del recurso presentado debe ser acogido".

\section{b) Voto particular a la Sentencia}

La argumentación anteriormente expuesta adolece, en nuestra opinión, de algunos defectos, que pone de relieve el Magistrado Conde Martín de Hijas en su voto particular a la Sentencia. Dice este Magistrado que la resolución de la cuestión planteada requería un pronunciamiento del Tribunal sobre una circunstancia fáctica: si la no participación de la diputada en la votación se debió a un funcionamiento incorrecto del sistema de voto electrónico instalado en su escaño o a la falta de debida diligencia de dicha diputada, que no había introducido a tiempo la tarjeta para efectuar la votación, no compartiendo la imposición a los órganos de la Cámara, y en concreto a su Presidente, de la tarea de demostrar que la diputada tuvo un comportamiento negligente, cuando la imputación de la carga de la prueba, presupuesto del razonamiento de la sentencia, podía haberse sostenido sobre otras bases.

Como señala el Magistrado, el deber de vigilancia sobre la negligencia de los diputados a la hora de votar que se impone al Presidente de la Cámara resulta difícil de articular, y puede generar no pocos problemas al funcionamiento ordinario de los Parlamentos, pareciendo más bien que el deber que puede y debe imponerse a los órganos de la Cámara y en particular a su Presidente es el de velar por el correcto y adecuado funcionamiento del sistema de votación que en cada caso se utilice.

La Sentencia afirma que de los datos que obran en el expediente y de las alegaciones de las partes se deduce que no se ha podido probar de manera irrebatible que la diputada cometiera un error en la votación. Tal deducción no resulta consistente para el Magistrado, porque no precisa los datos sobre la que se sustenta, sin que baste la referencia a las alegaciones de las partes, de las que podrán inferirse, obviamente, conclusiones absolutamente distintas.

Frente a ello, el Magistrado considera que el pronunciamiento del Tribunal debía haber partido del deber del Presidente de velar por el adecuado funcionamiento del sistema de votación empleado, para determinar a continuación, una vez constatado si el sistema de votación había funcionado o no correctamente, si el Presidente de la Cámara, al no repetir la votación, había 
vulnerado o no el derecho de la diputada recurrente en amparo. Existirían elementos en las actuaciones para sustentar tanto la imputación al Presidente de la Cámara de la carga probatoria correspondiente, como la conclusión a la que, a partir de esa imputación, llega el Tribunal: hay una base indiciaria para sostener que el sistema de votación podría no haber funcionado de modo correcto en las observaciones sobre el resultado que realiza el Presidente, que no se corresponden con el resultado final.

A partir de ese dato documentalmente acreditado podía establecerse la tesis de que era carga que incumbía al Presidente la de demostrar el adecuado funcionamiento del sistema de votación, atendiendo a las advertencias efectuadas al efecto por el portavoz del Grupo parlamentario Socialistas Vascos. Para el Magistrado, es la falta del cumplimiento de esa carga en esas concretas circunstancias, y no tanto la del incumplimiento de la carga de demostrar la falta de diligencia de la diputada, la que permite imputar al Presidente de la Cámara la actuación incorrecta de no haber mantenido la debida y exigible diligencia en preservar el ejercicio del derecho al voto de la diputada solicitante de amparo y la consecuente lesión de ese derecho. En definitiva, lo que puede, y debe, exigírsele a los órganos de la Cámara, y en concreto a su Presidente, es que velen por el adecuado funcionamiento del sistema de votación al que en cada caso se recurra, no por la diligencia o negligencia de los diputados al efectuar la votación.

\section{c) Comentario}

Con independencia de la relevancia de su objeto, y de las circunstancias fácticas que lo rodean, se plantea en esta sentencia la cuestión del error en las votaciones parlamentarias, y si es posible la repetición de las mismas.

A este respecto podemos señalar que el Reglamento del Parlamento Vasco no prevé - como tampoco el Reglamento del Congreso de los Diputados ni el del Senado- la anulación y repetición de aquellas votaciones en que el resultado no responde a la voluntad de la Cámara, por error o deficiente funcionamiento del sistema (electrónico). Esto último, a veces, no es imputable al mismo, sino a la comprensible inexperiencia en su funcionamiento por sus usuarios al comienzo de la legislatura o en otras situaciones. El procedimiento electrónico juega a veces malas pasadas, sobre todo cuando sus señorías están menos avezadas en su uso.

Pese a ello, en el Congreso no existen precedentes de que se haya repetido una votación en el Pleno, aunque se conozca con toda certeza que un grupo ha expresado erróneamente su voluntad, lo que ha influido en el resultado. Sí puede ocurrir que, en el curso de una votación que el Presidente declara iniciada, la anule antes de finalizar el tiempo para que los diputados pulsen su botón de voto porque aprecie que ha enunciado incorrectamente el objeto de la votación (números de enmiendas o identificación de la parte del dictamen, por ejemplo). 
Pero, más allá de esta rectificación sobre la marcha, el resultado erróneo es proclamado como tal ${ }^{1}$ En su caso, el diputado o grupo que se ha equivocado, hará constar, a efectos del Diario de sesiones, el verdadero sentido de su voto. Un ejemplo claro a este respecto constituye la aprobación de una enmienda a la totalidad por error en la votación por parte del Grupo Popular en la VII legislatura ${ }^{2}$. No se repitió la votación, y la devolución del proyecto tuvo que ser corregida mediante el envío de un nuevo proyecto de ley por el Gobierno, cuyo acuerdo de solicitud de tramitación por el procedimiento de urgencia se fundamentaba en el error padecido en la Cámara.

No obstante, la práctica de no repetición comienza a resquebrajarse en la VIII legislatura. El 23 de septiembre de 2004, ante la acusación de un diputado de enunciado confuso de la votación, el Presidente del Congreso, tras dar lectura al Diario de sesiones y uen función de la capacidad de ordenación de los debates que tengo, asumiendo que el Presidente haya cometido un error", procede a repetir la misma, sin que nadie se oponga ${ }^{3}$.

A diferencia de la rigidez con que se ha aplicado en el Congreso la imposibilidad de anulación de una votación celebrada ${ }^{4}$ (salvo cuando no ha funcionado el sistema y se anula antes de que tenga lugar), constan en el Senado algunos supuestos de anulación de una votación válidamente celebrada en Pleno $^{5}$, bien por decisión del Presidente en el curso del debate, bien por acuerdo de la Mesa, como la anulación posterior (acuerdo de 13 de mayo de 1991) de las votaciones realizadas sobre el Proyecto de Ley del Impuesto sobre la Renta de las Personas Físicas ${ }^{6}$, respecto de las cuales la prensa había publicado fotos que probaban el voto de unos senadores por otros, incluso

1 Véase por ejemplo Diario de sesiones del Pleno del Congreso núm. 25, de 21 de julio de 2004, pág. 1123. Puede verse un supuesto diferente, de protesta porque el resultado no se ajustaba al número real de diputados presentes en la Cámara, en el Diario de sesiones núm. 155, de 18 de abril de 2002.

2 Consta en el Diario de sesiones de Pleno del Congreso, núm. 66, de 8 de marzo de 2001. Enmienda a la totalidad de devolución presentada por el Grupo Socialista al Proyecto de ley de reforma del texto articulado de la Ley sobre tráfico, circulación de vehículos a motor y seguridad vial.

3 Diario de sesiones de Pleno del Congreso, núm. 33, de 23 de septiembre de 2004, pp. 1425-1426. Sí existen precedentes de anulación de votaciones en curso, con mayor o menor fortuna en el anuncio de dicha anulación al Pleno de la Cámara. Véase, por ejemplo, en relación con una moción, el Diario de sesiones del Congreso núm. 79, de 5 de abril de 2005, pág. 3857.

4 Véanse, por ejemplo, Diario de sesiones del Congreso núm. 56, de 10 de marzo de 1994 , pp. 2763 y ss., y núm. 193 , de 12 de noviembre de 1998, pp. 10289 y ss.

5 R.M. ${ }^{a}$ Fernández Riveira (El voto parlamentario, Centro de Estudios Políticos y Constitucionales, Madrid, 2003, pp. 314 y ss.) recoge el precedente — citado a continuación en el textode repetición de votaciones en el Pleno del Senado y algún otro de anulación por problemas técnicos en el reloj que marcaba el tiempo de votación (Diario de sesiones del Senado núm. 25, de 17 de diciembre de 1996, pág. 972) o por error (Diario de sesiones del Senado núm. 113, de 15 de diciembre de 1998, pág. 5427). Los más antiguos del lugar recordamos también, fuera del procedimiento legislativo, la anulación de la elección de don Carlos Ollero Gómez como Consejero del Tribunal de Cuentas por la confusión producida en sus apellidos, el 28 de junio de 1982, repitiéndose la elección al día siguiente. (Véase Diario de sesiones del Senado núm. 167, de 29 de junio de 1982, pp. 8242-8243).

6 Véase el Diario de sesiones del Senado núm. 69, de 16 de mayo de 1991, pág. 3801. 
con el pie, lo que dio lugar a la repetición de las votaciones en otra sesión plenaria.

Obviamente, se entiende siempre que sólo cabe repetir una votación si nadie se opone a ello ${ }^{7}$. Esto se ha quebrado, no obstante, al inicio de la VIII legislatura ${ }^{8}$.

En todo caso, creo que sería bueno introducir en los Reglamentos la posibilidad de repetición de una votación manifiestamente errónea o deficiente (posibilidad prevista en algún Reglamento autonómico, como por ejemplo en el artículo 127.2 del Reglamento de la Asamblea de Madrid) ${ }^{9}$, si ningún miembro de la Cámara se opone, cautela que protegería a las minorías de cualquier intento de maniobra, pero que permitiría enderezar determinados resultados que obviamente no se corresponden con la voluntad de la Cámara.

Formuladas estas consideraciones generales, los hechos concretos contemplados en la Sentencia muestran la existencia de dos circunstancias sobre las que podía o debía, en mi opinión, haber girado aquella:

En primer lugar, debió ser objeto de comprobación si la denuncia de la diputada de que su sistema de votación no le permitía votar se realizó dentro del tiempo hábil para emitir el voto (los veintidós segundos a que aluden los antecedentes) o terminado ese plazo, comprobación relativamente fácil en principio (a salvo las peculiaridades del Parlamento Vasco) con las grabaciones orales o gráficas de la sesión. Si la reclamación se realizó antes de terminar el tiempo de votación, quedaría invalidada la argumentación de la representación del Parlamento Vasco sobre la negligencia de la diputada. Y la verificación de los hechos podía haber sido realizada por el Tribunal Consti-

7 Así, en el Diario de sesiones del Senado núm. 146, de 17 de diciembre de 1992, pp. 81968198, se recoge un supuesto de error del Grupo Popular en cuanto al objeto de una votación, que el Presidente y distintos grupos parlamentarios manifestaron no tener inconveniente en repetir. La oposición de un senador de Izquierda Unida (aunque el portavoz del Grupo Mixto había admitido la repetición) motivó que ésta no se produjera. Aunque el Senador citado declaró finalmente su disposición a ausentarse del Pleno para que "se pongan de acuerdo los grupos mayoritarios", el portavoz del Grupo Popular manifestó que sería suficiente con que el debate constara en el Diario de sesiones.

8 Véase el Diario de sesiones del Senado núm. 3, de 12 de mayo de 2004, pág. 5961, en que el Presidente repite la votación de una moción a solicitud de los representantes de varios grupos parlamentarios que alegaron no haber oído la expresión "comienza la votación", y a pesar de la protesta del representante del grupo mayoritario .

9 Según el cual, "a petición del portavoz de un grupo parlamentario, el Presidente podrá, en caso de duda razonable sobre el resultado de la votación, ordenar un nuevo recuento de los votos, o incluso, que se repita la votación". Sería una versión actualizada del nuevo recuento o cómputo de los votos que los Reglamentos del Congreso de los Diputados y el Senado de 1982 prescriben, el primero para la votación ordinaria levantándose y sentándose, el segundo, para la votación por bolas o papeletas, en sus artículos 84.1 y 99.2, respectivamente: Art. 84.1 RC: “...El Presidente ordenará el recuento por los Secretarios si tuviera duda del resultado o si, incluso después de proclamado éste, algún grupo parlamentario lo reclamare". Art.99.2 RS: "En el caso de duda entre los Secretarios o cuando así lo soliciten veinticinco Senadores tratándose de sesión plenaria y cinco se se trata de sesión de Comisión, se procederá a un nuevo cómputo con la colaboración de dos Senadores designados por el Presidente y pertenecientes a distintos Grupos parlamentarios. 
tucional ${ }^{10}$, recabando en su caso una ampliación de las actuaciones remitidas, teniendo en cuenta la especialidad procedimental que presenta el recurso de amparo frente a decisiones emanadas de los órganos de las Asambleas legislativas (directamente impugnables cuando de acuerdo con sus normas internas son firmes, sin intervención previa judicial en la que pueda haberse desarrollado una actividad probatoria) y más aún en este caso, en que ni siquiera hubo un examen de los hechos por la Mesa, al descartar la misma la reconsideración de la decisión del Presidente.

Obviamente, aunque la reclamación de la diputada hubiera sido en tiempo, la Presidencia podía no haberlo advertido con la antelación suficiente como para haber anulado la votación en curso. ¿Debía haberlo hecho, si lo hubiera advertido? De no advertirlo a tiempo, ¿đebía anular la votación ya realizada? Hemos visto que los usos parlamentarios suelen ser contrarios a la repetición de las votaciones, por un principio de seguridad jurídica y también, por qué no, de protección de las minorías. Pero en este caso concreto concurría una segunda circunstancia, que también merece ser destacada.

Esta segunda circunstancia, que el Presidente debió tener en cuenta al adoptar su decisión, es que el voto de la diputada era esencial para el resultado, de manera que de la manifestación de la diputada se deduce que el acuerdo de la Cámara proclamado no se corresponde con la voluntad real de la misma. Parafraseando el artículo 113 de la Ley Orgánica del Régimen Electoral General, la invalidez de una votación no ha de comportar necesariamente la repetición de la misma cuando la rectificación de las deficiencias o errores no altere el resultado. O dicho de otra manera, la reclamación -relativamente frecuente después de una votación- de un diputado de que no ha podido votar, con independencia de cuál sea su causa, se salda con la declaración de la Presidencia de que ello constará en el Diario de Sesiones, a veces incluso expresando el sentido de su voto ("He querido votar en contra de...o a favor de..."), reparación suficiente cuando no afecta al resultado.

Es esta segunda circunstancia la que debió llevar al Presidente a extremar la diligencia en la comprobación, no sólo porque estaba en juego el derecho de voto de un diputado, sino también porque de ella dependía que la voluntad de la Cámara hubiera sido correctamente expresada y reflejada en el acuerdo adoptado. De ello era perfectamente consciente el Presidente, como se desprende de su alusión — no clara- a que había "babido un momento en que el empate se habia dado ya: 37 a 37", lo que vuelve a repetir ("quien preside esta sesión ha podido comprobar que en uno de los instantes se habia producido ya el 37-37"). Ese "ya" dos veces reiterado parecería dar a entender que también en esa ocasión el resultado era 37-37, y no 37-36 como aparecía en el panel electrónico. Disparidad, unida a la reclamación de la diputada,

10 La presunción sentada por la Sentencia de que, salvo prueba indubitable en contrario, la diputada actuó correctamente —entre otras cosas porque ningún interés puede suponérsele en crear una situación en la que ella y su grupo fueron los principales perjudicados» conducta dolosa de dicha diputada (el error provocado o voluntario), pero no es aplicable a la actuación negligente (la tardanza en emitir el voto o el error involuntario). 
tanto más si fue en tiempo, que habría debido dar lugar a una comprobación por la Presidencia, cuya ausencia permite hablar de actitud negligente por su parte, dada la trascendencia de la decisión.

Estas circunstancias, aquí simplemente apuntadas y probablemente con cierta torpeza, deberían haber sido planteadas y resueltas por la Sentencia en el sentido que considerara oportuno. Es la falta de argumentación de su conclusión la que reprocha el voto particular del Magistrado Conde Martín de Hijas, al igual que un comentario a la Sentencia de Pulido Quecedo ${ }^{11}$, que rechaza también el criterio, poco realista y de difícil aceptación como criterio general, de que corresponde al Presidente, en caso de duda sobre la validez de una votación, demostrar la negligencia del diputado.

En resumen, coincidimos con el voto particular de la sentencia en que la resolución de la cuestión requería un pronunciamiento sobre los hechos (que debían haberse indagado, añadimos) y en que el deber genérico que recae sobre los órganos de la Cámara, y en especial sobre su Presidente, no es demostrar que un diputado tenga una conducta negligente algo difícil de probar, sino asegurarse, o al menos poner todos los medios para verificar que los sistemas de votación funcionan o han funcionado correctamente, y tomar las medidas oportunas en caso contrario. Es decir, lo que corresponde a la Presidencia es observar la máxima diligencia en el ejercicio de su función y no incurrir ella misma en negligencia. En este sentido, cabe afirmar con Pulido que la doctrina de la STC 361/2006 no debería hacer jurisprudencia, aunque acierte en el fondo.

\section{El (DERECho AL) VOto De los GRUPos Parlamentarios}

\section{a) La posición del Tribunal}

La segunda cuestión abordada por la Sentencia, y resuelta en unos pocos párrafos, es la legitimación del grupo parlamentario en el proceso que nos ocupa. Partiendo de la representación institucional de los miembros que los integran, que la doctrina consolidada del Tribunal Constitucional reconoce a los grupos parlamentarios, otorgándoles capacidad procesal para defender las eventuales vulneraciones de los derechos fundamentales de sus miembros en relación con el ejercicio de su cargo representativo (SSTC81/1991 y 177/2002), declara sin más que entre ellas "se incluyen sin duda...las que tengan que ver con el ejercicio del derecho al voto de los parlamentarios". El portavoz del Grupo Socialista acciona para proteger los derechos de los que forman parte de aquél y, en concreto, el de manifestar su postura colectiva sobre un determi-

11 M. Pulido QueCEDo, "El Grupo parlamentario como titular del "derecho de voto colectivo", Repertorio Aranzadi del Tribunal Constitucional, núm. 21-22/2007. Pulido afirma que, aunque la Sentencia acierte en el fondo, lo hace con una motivación poco convincente y escasamente ajustada a los intersticios y funcionalidad de la vida parlamentaria. 
nado proyecto legislativo, que se había visto afectado por la vulneración del derecho al voto de uno de sus miembros. El Tribunal declara que no puede oponerse ninguna duda a la representación del portavoz para plantear la vulneración del derecho fundamental de los miembros del mismo, y del grupo como tal, pues se les ha privado de la efectividad de su voto que, en unión del de la diputada, hubiera supuesto la no aprobación de un proyecto de ley con el que habían mostrado su desacuerdo en el trámite de intervenciones que había precedido al acto de la votación. "Se ha lesionado en este caso el derecho, tanto de los parlamentarios como del grupo, a expresar su rechazo colectivo a una medida legislativa, y a que dicho rechazo tuviera unas consecuencias claras, consistentes en la no aprobación de la misma", derecho que "puede deducirse de la posición de los grupos parlamentarios en el Parlamento Vasco, que podría ilustrarse con la reproducción de numerosas normas de su Reglamento, puesto que en dicha Cámara, como en todas las democráticas de nuestros dias, estos grupos tienen asignado un papel decisivo en el ejercicio de las funciones básicas de las asambleas legislativas".

\section{b) El voto particular}

Sobre esta segunda cuestión manifiesta también su discrepancia el Magistrado Conde Martín de Hijas en su voto particular, que acertadamente recuerda que el derecho al voto concernido en este recurso es un derecho personal y no delegable de cada diputado como titular del escaño, no de los grupos parlamentarios en los que los diputados se integran, "de modo que el grupo parlamentario ningún derecho tiene, ni siquiera expectativa, a que todos sus integrantes voten en un determinado sentido para expresar asi "su rechazo colectivo". Salvo en los supuestos expresamente previstos en los Reglamentos de la Cámaras en los que se otorga al representante o portavoz de cada grupo parlamentario el mismo número de votos que miembros tiene el grupo, por tratarse de órganos internos en los que se quiere reproducir la composición del Pleno de la Cámara, el grupo parlamentario no es titular de ningún supuesto "derecho de voto colectivo". Evidentemente los grupos pueden dirigir instrucciones a sus miembros respecto al sentido de voto, pero tales instrucciones no vinculan jurídicamente al diputado, que es el titular del escaño y en cuanto tal el titular en este caso del ejercicio del derecho de voto que se ha visto cercenado".

El Magistrado considera un grave y peligroso error "en un plano estrictamente jurídico y constitucional (otra cosa es el sentido de la afirmación en un plano político), hablar de un derecho de los grupos meramente parlamentarios "a expresar su rechazo colectivo a una medida legislativa". Tal hipotético derecho o se vincula al derecho al voto, con lo que se estaría afirmando la simultánea titularidad de ese derecho por parte del diputado y por la del grupo en que se integra, lo que resulta contrario al carácter individual del derecho al voto que acabamos de afirmar y carece de la más minima base legal; o se configura como un derecho autónomo desvinculado del derecho al voto, y de ti- 
tularidad subjetiva diferenciada de la de este último derecho, concepción que tal vez sea la que aflora en la Sentencia, para cuya aceptación en términos jurídicos era inexcusable fijar la norma constitucional o infraconstitucional que la sustenta, lo que no se hace». Finaliza el voto particular destacando que en este proceso comparecen simultáneamente la diputada individualmente afectada en su derecho, reclamando su tutela de modo personalizado y propio, y el grupo, dándose así una peculiar concurrencia de dos legitimaciones para la defensa de un mismo derecho, lo que tiene difícil explicación.

\section{c) Comentario}

He tenido ocasión de ocuparme del predominio de los grupos parlamentarios en el ejercicio de la función legislativa ${ }^{12}$, primordial de las Asambleas representativas, como una manifestación más de la grupocracia que rige en nuestras Cortes Generales, a su vez reflejo de la partitocracia predominante en el moderno Estado de partidos, que origina un protagonismo absoluto de los grupos parlamentarios sobre los parlamentarios individuales. Este fenómeno ha sido obviamente fruto de la regulación contenida en los Reglamentos de las Cámaras, puesto que la Constitución sólo dos veces menciona a los grupos parlamentarios: la primera, con este nombre, al establecer la composición de la Diputación Permanente (artículo 78); en la otra ocasión (artículo 99.1) se refiere a "los grupos políticos con representación parlamentaria", que son consultados por el Rey con carácter previo a la propuesta de candidato a Presidente del Gobierno. En este caso, se ha optado por una interpretación más amplia que la de grupo parlamentario, pues el Rey consulta también a los representantes de las distintas formaciones que integran el Grupo Mixto.

Deriva, pues, de los Reglamentos parlamentarios el protagonismo de los grupos, acentuado por la práctica y los precedentes, que se manifiesta en los distintos procedimientos a través de los que se articula el ejercicio de las funciones de las Cámaras (legislativa, presupuestaria, de control, de nombramiento), así como en distintos aspectos de su organización y funcionamiento (designación de miembros de comisiones y ponencias, conversión de los debates en turnos de los portavoces designados por los grupos, de forma que el parlamentario intervendrá en nombre de su grupo o no intervendrá).

La explicación que se quiere dar a la posición de los grupos parlamentarios es la misma que se aplica a los partidos políticos en la vida política: constituyen la proyección de las opciones políticas legitimadas a través del sufragio, y, por tanto, el papel privilegiado que reciben en la reglamentación de todos los procedimientos parlamentarios tiene su razón de ser no sólo en la funcionalidad de las Cámaras (que tampoco podrían funcionar ágilmente sin intentar agrupar de alguna forma las trescientas cincuenta o

12 Puede verse P. García-Escudero Márquez, El procedimiento legislativo ordinario en las Cortes Generales, Centro de Estudios Políticos y Constitucionales, Madrid, 2006, pp. 70 y ss. 
doscientas cincuenta y nueve voces y voluntades), sino en que los grupos manifiestan institucionalmente el pluralismo político propio de las sociedades complejas.

Ahora bien, en esta situación de predominio del grupo sobre el parlamentario que constituye el signo de los tiempos, debemos abogar por la no suplantación absoluta de los representantes por los grupos que ellos crean. Llevado al extremo, podrían reducirse las Cámaras a una Junta de Portavoces con voto ponderado en función de los resultados electorales. Sabemos que la disciplina de voto coarta realmente la posibilidad de libre ejercicio de su función por los parlamentarios individuales, pero cabe sostener que al menos en el plano teórico debe garantizárseles la participación en los procedimientos con un mínimo de autonomía. Si la relación representante-elector se ha visto sustituida por la relación representante-partido-elector, incluso fraccionada en dos (representante-partido, partido-elector) o reducida a la relación partido-elector ${ }^{13}$, ello no debe propiciar que el llamado mandato de partido viole la prohibición de mandato imperativo proclamada por el artículo 67.2 de la Constitución ${ }^{14}$.

Es precisamente en relación con la prohibición constitucional del mandato imperativo, así como con la proclamación del voto como personal e indelegable en el artículo 79.3, como se plantea la posible inconstitucionalidad del voto ponderado $^{15}$, implantado primero en las ponencias ${ }^{16}$ e incorporado al Reglamento del Congreso como forma de adopción de acuerdos en la Junta de Portavoces (art. 39.4) y en las comisiones de investigación (art. 52.3, tras la reforma de 1994), al Reglamento del Senado en la Comisión de Nombramientos (art. 185.2) y a ambos como forma de resolver los empates en comisión (88.2 RC, reforma de 23 de septiembre de 1993; 100.4 RS, reforma de 24 de octubre de 1995) ${ }^{17}$.

Hemos apuntado en otro lugar ${ }^{18}$ las dificultades que plantea la aceptación de la ponderación del voto en las comisiones, órganos de trabajo de la Cá-

13 Véase A. GARRORENA MORALES, "Apuntes para una revisión crítica de la teoría de la representación", en El Parlamento y sus transformaciones actuales, A. Garrorena Morales (ed.), Tecnos, Madrid, 1988, págs.46 y ss.

14 Recuérdese la doctrina del Tribunal Constitucional, iniciada con las sentencias 5/1983, de 4 de febrero y 10/1983, de 21 de febrero, a favor del mandato representativo y, en suma, de la relación elector-representante.

15 Las dos notas del voto como personal e indelegable atribuyen, como dice R.M. ${ }^{a}$ FERNÁNDEZ RIVEIRA (El voto parlamentario, cit., pág. 111), "la completa y absoluta titularidad de tal derecho al parlamentario individual. Ello resulta... de dificil armonización con algunas prácticas incluso reconocidas normativamente, como las votaciones ponderadas, las votaciones sometidas a disciplina de grupo, etc.».

16 Lo que durante legislaturas ocurría de facto se incorporó a la Norma interpretativa de la Presidencia del Senado de 18 de Noviembre de 1997 y a la Resolución de la Presidencia del Congreso de los Diputados de 18 de mayo de 2004

17 También, por vía de hecho, se aplica el voto ponderado en aquellas comisiones que no reproducen la composición del Pleno, como la Comisión del Estatuto de los Diputados. Por Resolución de la Presidencia del Congreso de 25 de mayo de 2000, se utiliza en la Comisión Consultiva de Nombramientos de esta Cámara.

18 P. GARCÍA-ESCUDERO MÁRQUEZ, El procedimiento legislativo ordinario en las Cortes Generales, cit., pp. 74-75. 
mara que preparan el trabajo del Pleno o incluso lo sustituyen (cuando actúan con competencia legislativa plena, por ejemplo) en el ejercicio de funciones de la Cámara, de ahí su composición proporcional a la de aquél. De conformidad con el artículo 79.3 CE, no cabe la delegación de voto por los parlamentarios en el ejercicio de sus funciones. Por eso sólo con dificultades cabe aceptar la ponderación de voto en comisión, atendiendo a que las previsiones reglamentarias lo aplican sólo como técnica, no ya para dirimir un empate, sino para entender que éste no se produce.

La afirmación de la Sentencia de que el derecho al voto de los parlamentarios se incluye sin duda entre las eventuales vulneraciones de derechos fundamentales respecto de las que los grupos ostentan la representación de sus miembros, y el correlativo reconocimiento de la lesión de un derecho del grupo - al que se ha "privado de la efectividad de su voto que, en unión del de la diputada ..., hubiera supuesto la no aprobación de un proyecto de ley con el que habian mostrado su desacuerdo en el trámite de intervenciones que había precedido al acto de la votación" - "a expresar su rechazo colectivo a una medida legislativa, y a que dicho rechazo tuviera unas consecuencias claras, consistentes en la no aprobación de la misma", supone un salto cualitativo desde una situación - censurable y censurada- que se da en el mundo de la realidad al mundo del Derecho; o, como dice el voto particular a la Sentencia, constituye un grave y peligroso error hablar en un plano, no político, sino estrictamente jurídico y constitucional, de un derecho de los grupos parlamentarios a expresar su rechazo colectivo a una medida legislativa, vinculado al derecho al voto o independiente de él, pero en ambos casos sin base constitucional ni reglamentaria.

En efecto, el derecho al voto es un derecho típicamente individual de los representantes, cuya base se encuentra, respecto de diputados y senadores, en los artículos 79.3 (como personal e indelegable) y 67.2 (voto libre, desligado de mandato imperativo alguno) de la Constitución. Es este voto libre el que impide, salvo que se considere inexistente, admitir "el derecho al rechazo colectivo de una medida legislativa", porque sería tanto como dar por supuesto que la intención de voto del grupo, expresada en la intervención de su portavoz, es vinculante para sus miembros: esto es, admitir el constitucionalmente prohibido mandato imperativo en su forma moderna de mandato de partido. Carácter vinculante que sólo aparece, en términos más o menos velados (fijar la posición del grupo en los órganos de la Cámara), con su correspondiente sanción - normalmente económica- en los reglamentos internos de los propios grupos, documentos que no se hacen públicos ${ }^{19}$.

Reduciendo el argumento al absurdo, podemos plantearnos qué habría de entenderse por voto del grupo o voto colectivo, si sus miembros votan en dis-

19 Véase R. M. ${ }^{a}$ FERNÁNDEZ RIVEIRA, El voto parlamentario, cit., pp. 270 y ss. Esta autora considera como límite a las sanciones a los parlamentarios la prohibición del mandato imperativo (67.2 CE), pero también el artículo 23.2 en su interpretación jurisprudencial de mantenimiento independiente y libre en el ejercicio del cargo del representante (pág. 277). 
tinto sentido, voluntariamente o por error. ¿El emitido por la mayoría de ellos, por el diputado encargado de indicar el sentido del voto, por su portavoz titular? No debemos tampoco olvidar que existe un Grupo Mixto, de especiales características y composición heterogénea, al que no cabria aplicar ninguno de los razonamientos contenidos en la Sentencia.

Los Reglamentos del Congreso de los Diputados y del Senado reconocen a diputados y senadores el derecho al voto, de forma más explícita y también como deber en el $\mathrm{RS}^{20}$. Sobre el mismo gira la regulación de las votaciones, de forma que los grupos parlamentarios sólo aparecen en ella como legitimados para solicitar la comprobación de quórum en el Senado (93 RS) o para solicitar en ambas Cámaras votación nominal pública (85 RC, 96 RS), y en el Congreso votación secreta (85 RC) o explicación de voto (89 RC; explicación que, coherentemente, no cabe en la votación secreta, 89.3 RC). En ambos Reglamentos, como se ha señalado, se ha introducido el voto ponderado para dirimir los empates en las comisiones (88.2 RC, 100.4 RS).

A su vez, el Reglamento del Parlamento Vasco proclama en su artículo 11 el derecho y el deber de los parlamentarios a asistir a las sesiones del Pleno y de las Comisiones de que formen parte, así como a desempeñar las funciones a que reglamentariamente vengan obligados. Al regular las votaciones, se refiere en todo momento a los parlamentarios, incluso como titulares del derecho a reclamar la comprobación del quórum. Sólo están facultados los grupos para reclamar nuevo cómputo en la votación ordinaria, en la línea expuesta del Reglamento del Congreso de los Diputados (74.a RPV) o para solicitar votación nominal o secreta. Aparecen indicios del mandato de partido en la aplicación del voto poderado en caso de empate en las comisiones (80.2 y 31.b.2 RPV; no así para el Pleno, en el que los empates, como hemos visto en el apartado anterior, reiterados en dos votaciones más en dos sesiones distintas, suponen el rechazo) y en la explicación de voto por el grupo parlamentario que cambie el sentido de su voto como consecuencia del debate (83 RPV; el artículo 81 admite también la explicación de los miembros de la Cámara autores de una propuesta).

Pulido Quecedo ${ }^{21}$, en relación con el "desliz» en que incurre en este punto la Sentencia que nos ocupa, califica de "afirmación apodictica y no fundada" que "sonrojaría a cualquier especialista en Derecho parlamentario" el argumento contenido en aquella de que el derecho colectivo del grupo parlamentario a rechazar una medida legislativa "puede deducirse de la posición de los grupos en el Parlamento Vasco, que podría ilustrarse con la reproducción de numerosas normas de su Reglamento"; argumento desafortunado que

20 Art. 6.1 RC: Los diputados tendrán el derecho de asistir con voto a las sesiones del Pleno y a las de las Comisiones de que formen parte... Art. 20.1 RS: Los senadores tendrán el derecho y el deber de asistir a las sesiones plenarias y a las de las Comisiones de que formen parte, y a votar en las mismas, así como a desempeñar todas las funciones a que reglamentariamente vengan obligados.

21 M. PULIDO QUECEDO, "El Grupo parlamentario como titular del "derecho de voto colectivO", cit. 
repristinaría una suerte de voto ponderado en el Pleno de la Cámara y que supone desconocer, añade, cómo funciona tal modalidad de voto en el Parlamento, inexistente en el Pleno. Obviamente, rechaza también que la legitimación del portavoz de un grupo provenga de un presunto derecho de voto colectivo del grupo o de lo que la Sentencia denomina "postura colectiva del grupo".

De lo expuesto hasta ahora resulta evidente que compartimos estas críticas, como también las contenidas en el voto particular. Si el escaño - por el momento y en sentido figurado-, dado que es el grupo parlamentario quien asigna un lugar concreto en el Salón de sesiones pertenece al diputado (ex SSTC 5 y 10/1983, entre otras), y no al partido ni al grupo, el derecho al voto, como forma de ejercer el cargo representativo participando en la formación de la voluntad del Parlamento, corresponde también a aquél, y debe continuar correspondiéndole con claridad y sin fisuras, cuando menos en el ámbito normativo y de la jurisprudencia constitucional ${ }^{22}$. Recordemos también que, cuando la Constitución quiere reconocer un derecho a las minorías parlamentarias para recurrir la inconstitucionalidad de las leyes (que puede derivar de incorrecciones formales o de procedimiento, y no sólo materiales), atribuye la legitimación a cincuenta diputados y cincuenta senadores, como titulares que son individualmente del mandato parlamentario, y no a los grupos.

En conclusión: el derecho al voto forma parte del estatuto jurídico del parlamentario, derivado de su mandato representativo, e integra el núcleo irreductible de su ius in officium amparado en el artículo 23.2 de la Constitución. La legitimación que en el recurso de amparo se reconozca a los grupos parlamentarios no parece pueda fundarse en un supuesto derecho colectivo al voto por parte del grupo ${ }^{23}$, no reconocido en la Constitución ni en los Reglamentos parlamentarios.

22 Una primera consecuencia de la doctrina sentada por la Sentencia puede verse en el Diario de Sesiones del Congreso núm. 281, de 13 de septiembre de 2007, p. 13899: ante la manifestación de una diputada de que se le había estropeado el aparato de votación en las dos últimas votaciones, el Presidente responde que "los letrados aumentarán automáticamente lo que se supone es el voto general del Grupo Socialista", aclarando, ante las reservas formuladas por el representante del Grupo Popular, que ese voto no afectaba al resultado. La propuesta más correcta y sencilla fue apuntada por el portavoz del Grupo Socialista, en el sentido de que (al tratarse de una votación pública) los diputados que tengan problemas con el sistema de votación puedan manifestar de viva voz o con la mano el sentido de su voto.

23 En palabras de M. Morales Arroyo, "El procedimiento de amparo contra las decisiones y los actos de los órganos legislativos", ejemplar mecanografiado, pág. 91, la consolidación de la doctrina contenida en la STC 361/2006, que concede al grupo no sólo la capacidad procesal para interponer en nombre del parlamentario un recurso de amparo, sino también la titularidad de un derecho constitucional afectado, que no se identifica y que el fallo inserta en el artículo 23.2 de la Constitución, provocaría un importante cambio en la jurisprudencia más ortodoxa sobre la posición de los cargos públicos representativos y la participación de los ciudadanos a través de ellos, con la exclusión en dicha relación de otros grupos como los partidos políticos o su representación institucional, los grupos parlamentarios. 


\section{OTRAS CUESTIONES}

Aunque la Sentencia no las contemple, o sólo incidentalmente, quisiera reseñar algunas otras cuestiones que me ha suscitado su lectura, sin pretender darles un tratamiento completo en este breve comentario, sino tan sólo formular algunas reflexiones.

\section{La irReCURribilidad ante la Mesa de las DeCisiones del Presidente en LA DIRECCIÓN DE LOS DEBATES}

En los antecedentes aparece mencionado un incidente de cierta relevancia en la vida de las Cámaras. Dado que la Ley Orgánica del Tribunal Constitucional exige, para recurrir en amparo, la firmeza de los actos de órganos parlamentarios con arreglo a las normas internas de las Asambleas, para asegurarse de esa firmeza el portavoz del grupo recurrente solicitó de la Mesa de la Cámara la reconsideración de la decisión del Presidente, rechazando aquélla por dos veces entrar en el examen del asunto por carecer de atribuciones para revisar las decisiones tomadas por el Presidente en el curso de una sesión plenaria ${ }^{24}$. En los Fundamentos Jurídicos simplemente se menciona, al identificar la decisión objeto del recurso, que la Mesa del Parlamento Vasco se negó a reconsiderarla, "decisión — ¿la de la Mesa? - confirmada definitivamente mediante certificación oficial de 2 de febrero de 2005", lo que la Sala da por bueno, pues entra en el fondo del asunto. Sin embargo, en el Fundamento Jurídico 6 y en el punto $2 .^{\circ}$ del fallo, al anular la decisión del Presidente del Parlamento Vasco, se desliza incorrectamente la afirmación de que fue "ratificada por otra posterior de la Mesa del citado Parlamento", anulándose también ésta.

Este incidente pone de manifiesto una deficiencia existente en la normativa parlamentaria. El Reglamento del Parlamento Vasco (al igual que el del Congreso de los Diputados, al que tomó como modelo, y el del Senado), sólo prevé, en términos tan vagos que ni siquiera establece un plazo para su presentación, la solicitud por diputados y grupos de reconsideración de los acuerdos de la Mesa adoptados en el ejercicio de sus facultades de calificación de escritos y de decisión sobre su admisibilidad y tramitación. La denegación de la reconsideración, es decir, la ratificación del primer acuerdo, es la que determina la firmeza del mismo que abre el recurso de amparo.

24 Como relata el apartado 2 de los Antecedentes, tras un primer acuerdo de toma de conocimiento por la Mesa, como quiera que el portavoz socialista entendió que no había recibido una repuesta expresa a su solicitud de reconsideración, instó la toma de acuerdo mediante nuevo escrito, "siéndole notificada posteriormente una certificación de fecha 2 de febrero de 2005, de la Mesa en la que ésta se ratificaba en que carecía de atribuciones para revisar las decisiones tomadas por el Presidente de la Cámara en el curso de una sesión plenaria". 
Sin embargo, como evidencia el caso que nos ocupa y también con relativa frecuencia la realidad parlamentaria, no prevén los Reglamentos recurso alguno respecto de los actos de ejercicio de las facultades que aquéllos atribuyen al Presidente de la Cámara, que son amplias en materia de dirección de los debates y disciplina parlamentaria. Es claro que la dinámica de las sesiones requiere una rapidez en las decisiones que no haría conveniente su revisibilidad. Pero también lo es que, en algunos casos, la comprobación posterior de datos y hechos (el equivalente a la moviola de los partidos de fútbol) permitiría poner de manifiesto algún error manifiesto de apreciación que hubiera conducido a una decisión susceptible de revisión (una hipotética sanción con error en la persona, por ejemplo).

Estas consideraciones llevarían a aconsejar incluir en los Reglamentos algún tipo de recurso ante el propio Presidente (los grupos hacen uso frecuente de la queja mediante escrito dirigido al mismo, solicitando o no alguna reparación), en materia de su competencia como es la dirección de los debates, que le permitiera resolver, en los casos en que ello fuera posible, con mayor conocimiento de causa. La ratificación en la decisión inicial permitiría contar además con el beneficio de la motivación, infrecuente o insuficiente en las decisiones que se adoptan sobre la marcha, como ha ocurrido también en el caso que nos ocupa.

\section{La aprobación de la Ley de Presupuestos como ejercicio}

\section{DE LA FUNCIÓN LEGISLATIVA}

Muy de pasada, el Fundamento Jurídico 4, al citar una sentencia que reconoce relevancia constitucional a los derechos o facultades atribuidos al representante que pertenezcan al núcleo de su función representativa parlamentaria, como son, indudablemente, el ejercicio de la función legislativa o de control del Gobierno, encuadra la aprobación de la Ley de Presupuestos en la primera ("...el ejercicio de la función legislativa [que es el caso de la Ley de presupuestos, objeto de la votación de la que trae causa el amparo solicitado]..."). Sabido es que, superadas hoy las dudas sobre su naturaleza legislativa y la disputa sobre si se trata de una ley sólo formal o material, la Ley de Presupuestos es una verdadera ley y el acto de su aprobación tiene carácter legislativo. No obstante, quisiera recordar solamente que la función presupuestaria de las Cortes Generales (materializada primordialmente en la aprobación de los presupuestos) aparece como independiente de la legislativa e inmediatamente después de la misma en el artículo 66.2 de la Constitución, y en los mismos términos respecto del Parlamento Vasco en el artículo 25.1 del Estatuto de Autonomía del País Vasco. Como el propio Tribunal Constitucional ha declarado (STC 3/2003, FJ. 4), en la aprobación de los Presupuestos concurren las tres funciones de las Cámaras, legislativa, presupuestaria y de control; si ha de destacarse una, debe ser a mi juicio la presupuestaria, de suficiente entidad como para entenderse incorporada al núcleo de la función representativa parlamentaria. 


\section{La problemática ejecución de las Sentencias tardías}

La doctrina ha destacado la ineficacia de las Sentencias declarativas ${ }^{25}$, tan frecuentes en el amparo frente a acuerdos de órganos parlamentarios que probablemente constituyen la regla, por ser dictadas cuando ha concluido la legislatura en que el acto o la decisión impugnada - por ejemplo, de inadmisión de una iniciativa - se produce, lo que impide el restablecimiento en el ejercicio del derecho lesionado.

Así ocurre también en este caso, en el que se justifica el carácter declarativo del fallo no sólo en la celebración de unas elecciones al Parlamento Vasco que tuvieron, entre otras consecuencias, la renovación de sus órganos directivos y de sus miembros, sino también en la vigencia anual ya concluida de la Ley de presupuestos del País Vasco para 2005. Ello provoca, "que (la) anulación (de la decisión impugnada) [no] suponga la necesidad de repetir la tantas veces citada votación dada la imposibilidad material de hacerlo asi” (FJ 6).

El carácter declarativo del fallo es criticado por Pulido, considerándolo derivado de la negativa de suspender el acto parlamentario durante la tramitación del amparo, como una práctica del Tribunal que debería corregir, pues la única fuerza de los Tribunales y máxime del Constitucional para pacificar asuntos es el decisum enérgico y eficaz, no las meras declaraciones de intenciones $^{26}$.

Tal vez la suspensión no sea siempre un instrumento adecuado. Pero lo que no cabe duda es que el paso del tiempo en ocasiones priva de eficacia a fallos que, en casos como el examinado, habrían tenido una trascendencia notable. Sin duda, esto puede llegar a ser hasta cómodo, cuando permite enjuiciar haciendo abstracción de las consecuencias que podría conllevar el fallo en un determinado sentido, pero debería llamar a reflexión a los implicados en la situación, incluido el propio legislador, que podría buscar alguna solución normativa para que las sentencias a que nos referimos surtan efectos reales, del mismo modo que en su día se obtuvo respecto de los recursos de amparo electoral.

25 Por todos, M. MORALES ARROYO, «El procedimiento de amparo contra las decisiones y los actos de los órganos legislativos", cit., pp. 161 y ss., donde incluye un listado de 15 sentencias emitidas con legislatura acabada (nota 353 ) de las 33 estimatorias respecto de actuaciones del poder legislativo.

26 "Se argumentará el valor pro futuro de la resolución, pero no es suficiente. Cuando un Tribunal no actúa sus potestades, su auctoritas se desvanece. Poca "auctoritas" y escasa "potestas" no son las mejores armas para hacer prevalecer la fuerza normativa de la Consitución.. M. Pulido Quecedo, "El Grupo parlamentario como titular del "derecho de voto colectivo",cit. 
ABSTRACT. The Constitutional Court, through its ruling 361/2006 on an appeal for the protection of constitutional rights (recurso de amparo), tried a case made against a resolution of the Speaker of the Basque Parliament denying the repetition a vote, resulting in the enactment of the 2005 Regional Budget. The ruling raised two questions: the Speaker's duties in relation to the member's behaviour when casting their vote in Parliament and the competency to appeal invested on the spokesperson of the parliamentary group to which the plaintiff member belonged. This comment examines the problems involved in parliamentary votes and disagrees, much in the same line as the Constitutional Court's minority view, with the reasoning of the ruling, insofar as it establishes the Speaker's duty to prove the member's negligence when the validity of a vote is in doubt. The author also disagrees with the parliamentary group's right to collectively reject an initiative, on the grounds that the Constitution enshrines the vote of the parliamentarians as personal and unbounded. This comment also points out other issues left unmentioned by the ruling, like the inability to appeal to the Bureau of the House against the Speaker's decisions relating to the conduct of the debates and the problem-prone execution of rulings once the legislature has expired, which makes these judgements merely declaratory. 